\title{
Josef Brudzinski and Vladimir Mikhailovich Kernig: Signs for Diagnosing Meningitis
}

\author{
Michael A. Ward; Tonia M. Greenwood; David R. Kumar, BS; \\ Joseph J. Mazza, MD and Steven H. Yale, MD
}

\section{Keywords: \\ Kernig \\ Brudzinski \\ Meningitis}

Corresponding Author:

Steven H. Yale, MD

Clinical Research Center

Marshfield Clinic Research Foundation

1000 North Oak Avenue

Marshfield, WI 54449

Tel.: 7| 5-387-9| I0

Fax: 715-389-3808

E-mail: yale.steven@marshfieldclinic.org

Received: June 3, 2009

Revised: July 23, 2009

Accepted: July 29, 2009

doi: $|0.3| 2 \mid / \mathrm{cmr} .2010 .862$
I

nflammation of the meninges, or meningitis, is a serious neurological insult that involves the membranes (dura, pia and arachnoid matter) covering the brain and spinal cord. Meningitis may be caused by any of a host of infectious and noninfectious agents including bacteria, viruses, fungi, parasites, drugs, autoimmune disorders, or malignancy which considerably influences morbidity and mortality. ${ }^{1}$ Currently, the case-fatality rate for adults with bacterial meningitis is approximately $25 \%$ with temporary or permanent neurologic sequelae occurring in $21 \%$ to $28 \%$ of survivors. ${ }^{2,3}$ These rates are slightly lower for children older than 1 month, but remain significant, and early diagnosis is critical in improving outcomes. ${ }^{4,5}$

Symptoms of acute meningitis include high fevers, chills, joint pain, decreased mental status, headache ("worst headache of my life"), stiff neck, photophobia, and rash. Early indicators such as rash or joint pain may present abruptly depending on the etiologic agent. One study reported that initial symptoms appear on average 24 hours prior to hospital admission. ${ }^{6}$ A major predictor of outcome in patients diagnosed with bacterial meningitis is the time that has elapsed from the onset of symptoms to the initiation of antibiotic treatment. $2,7,8$ Empiric treatment with selected antibiotics is based on age of the patient and associated co-morbidities.

Critical and timely diagnosis may be facilitated by Kernig's and Brudzinski's signs. These two eponyms are commonly associated with meningitis.

\section{Kernig's Sign}

Vladimir Mikhailovich Kernig (1840-1917) was a Russian-Baltic German clinical neurologist born in Lapaia, Latvia. He received the majority of his education at the Russian University. After receiving his medical doctorate in 1865, Kernig joined the Obuchow Hospital in St. Petersburg as a voluntary assistant physician. He later became a clinical teacher of Internal Medicine at the Empress Marie's institutions, a school for the deaf and mute, and was the head physician at Obuchow Women's Hospital from 1890 until World War I. 9,10 
Kernig's sign was first described in 1882 in an article from the St. Petersburg Medizinische Wochenschrift (German weekly medical writing) in which he stated:

"I have observed for a number of years in cases of meningitis a symptom which is apparently rarely recognized although, in my opinion, it is of significant practical value. I am referring to the occurrence of flexion contracture in the legs or occasionally also in the arms which becomes evident only after the patient sits up; the stiffness of neck and back will ordinarily become much more severe and only now will a flexion contracture occur in the knee and occasionally also in the elbow joints. If one attempts to extend the patient's knees one will succeed only to an angle of approximately $135^{\circ}$. In cases in which the phenomenon is very pronounced the angle may even remain $90^{\circ} . " 11$

Today the maneuver is performed with the patient in the supine position with hips and knees in flexion. The patient's knee is slowly extended; pain (spasms) involving the hamstring muscles as a result of stretching the inflamed sciatic nerve roots at angles less than $135^{\circ}$, with the popliteal fossa serving as the inner angle, constitutes a positive Kernig's $\operatorname{sign}^{10}$ (figure 1). Kernig did not describe pain in the original description of the maneuver. ${ }^{10,11}$ Nonetheless, many clinicians include pain as a required component constituting a positive test. 10

\section{Brudzinski’s Sign}

Josef Brudzinski (1874-1917), a Polish born pediatrician, also studied at the Russian University of Dorpat, and then practiced medicine in Poland. Dr. Brudzinski was an active leader in the medical and political community. After obtaining his medical degree in 1897, Brudzinski went to Germany to conduct research with Theodor Escherich, a pioneer in the field of pediatric infectious diseases. ${ }^{12}$ His work contributed to making the Anne Marie Children's Hospital in Lodz, Poland a model hospital of its time. In 1908, he launched

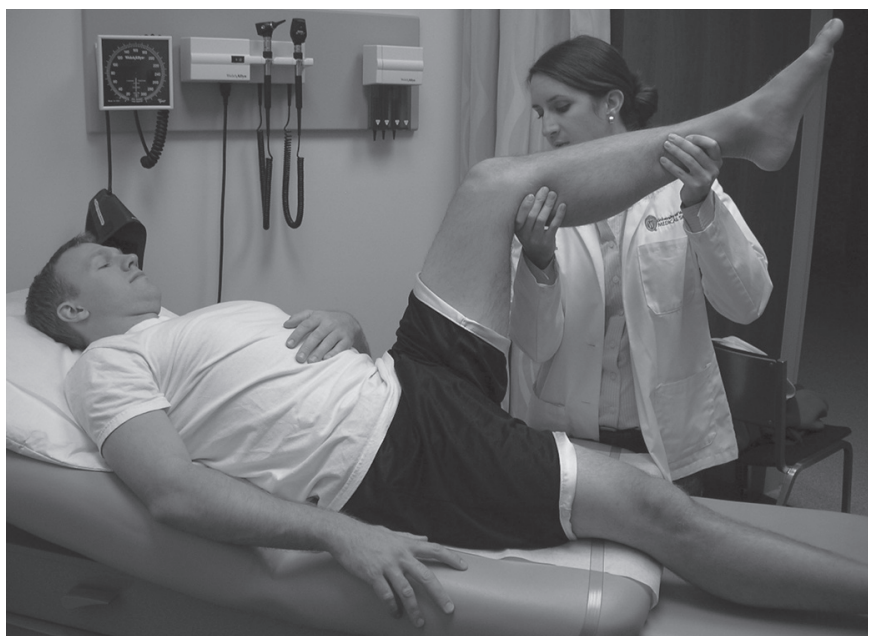

Figure 1. Kernig's sign. Flexing a patient's hip, then extending the knee causes pain at angles less than $135^{\circ}$ with the popliteal fossa as the inner angle.

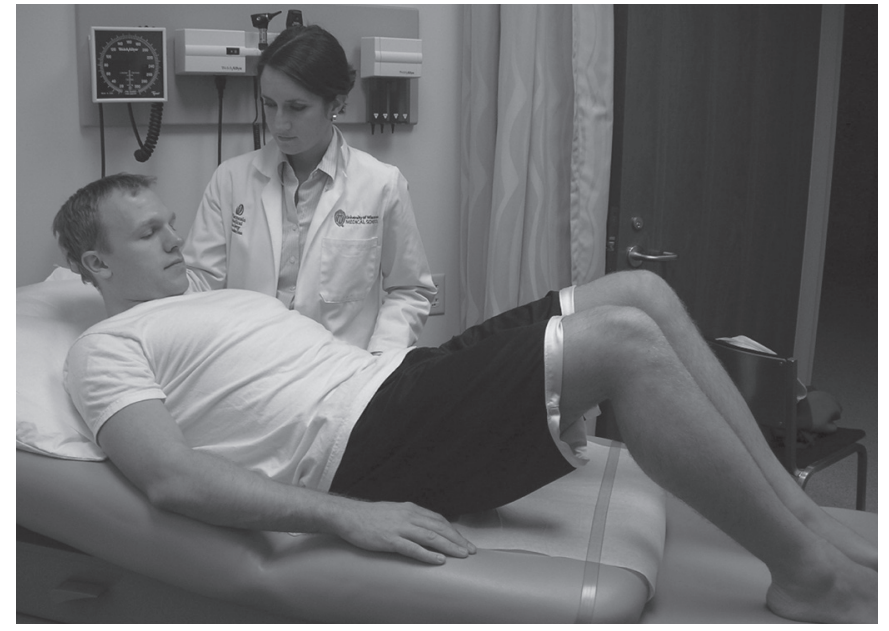

Figure 2. Brudzinski's sign. After passive flexion of the patient's neck, there is flexion of the hips and knees.

Poland's first journal of pediatrics, Przeglad Pedyatryczny, followed in 1910 by designing a children's hospital in Warsaw, Poland according to his own specifications. A separate outpatient clinic entrance, purposely constructed without hospital access, successfully prevented the spread of infections. ${ }^{13}$ Without question this blueprint spared large numbers of children from being exposed to diseases easily transmitted through airborne pathogens. Brudzinski was instrumental in reestablishing the Polish university in Warsaw after German occupancy during World War I and was named director at its 1915 opening.

Ahead of his time, Brudzinski relied on laboratory studies to provide explanations for the mechanisms of the numerous meningeal signs he described, specifically conducting experiments on different species of animals. ${ }^{10}$ Brudzinski developed four maneuvers to detect meningitis: the obscure Cheek sign, Symphyseal sign, Brudzinski's reflex, and the famous Brudzinski (nape of the neck) sign. A positive Cheek sign is elicited by placing pressure on both cheeks inferior to the zygomatic arch causing spontaneous flexion of the forearm and arm. ${ }^{10}$ A positive Symphyseal sign occurs when pressure applied to the pubic symphysis elicits a reflex hip and knee flexion, and abduction of the leg. Both of these signs were most commonly observed in children with meningitis caused by Mycobaterium tuberculosis. ${ }^{10}$ Brudzinski's reflex consists of passive flexion of one knee into the abdomen eliciting flexion of opposite hip and knee. ${ }^{11}$ His most famous maneuver is aptly referred to as Brudzinski's sign and is performed with the patient in the supine position. The examiner, with one hand behind the patient's head and the other on their chest, raises the patient's head while the other hand prevents the patient from rising. It is theorized that in meningitis, passive flexion of the neck stretches the nerve roots through the meninges, both of which are inflamed, causing pain and involuntary movement of lower extremities. Therefore, flexion of the patient's hips and knees after passive flexion of the neck constitutes a positive Brudzinski sign ${ }^{9,10}$ (figure 2). 


\section{Relationship Between Pathogen and Sensitivity of Signs}

In Brudzinski's 1909 paper entitled "Uber die kontralateralen Reflexe an den unteren Extremitatenbei Kindern" ("A New Sign of the Lower Extremities in Meningitis of Children"), the sensitivities of Brudzinski's and Kernig's signs were 97\% and $42 \%$, respectively. ${ }^{11}$ These findings were met with much opposition by his colleagues, but Brudzinski confirmed the high specificity of his sign by being unable to elicit it in children without meningitis. ${ }^{14}$ One cannot help but notice that these early sensitivities found by Brudzinski are much higher than what has been reported in more recent literature. ${ }^{15-18}$ Some attribute this to the fact that the two most common causes of meningitis during this time were Streptococcus pneumoniae and $M$. tuberculosis. The severe inflammation response that accompanies infection with $S$. pneumoniae likely plays a role in explaining the high mortality rates associated with pneumococcal infection (28\%) as compared to meningococcal infection (11\%) and Haemophilus infection (3-6\%). ${ }^{19,20}$ Since Kernig's and Brudzinski’s signs are related to inflammation of the meninges and nerve roots, the severity of inflammation that occurs in bacterial meningitis would likely result in greater sensitivity of the signs. ${ }^{11,14}$ The severity of nuchal rigidity, an indicator of meningeal irritation and probable inflammation, is also greater in tuberculous meningitis compared to other forms of pyogenic meningitis. ${ }^{21}$ A retrospective study conducted by van Well et $\mathrm{al}^{22}$ found meningeal irritation present in $98 \%$ of 554 patients with tuberculous meningitis. Furthermore, the progression of tuberculous meningitis is much slower than bacterial meningitis, resulting in a more advanced stage of the disease at presentation and initiation of treatment, increasing the likelihood that a patient would present with a positive Kernig's and/or Brudzinski's sign. ${ }^{21}$

The majority of examined patients described in Kernig's and Brudzinski's original papers were children; the population most frequently affected by tuberculous meningitis. ${ }^{22}$ Out of 554 patients with tuberculous meningitis in the van Well study, $82 \%$ were $<5$ years old. ${ }^{22}$ Moreover, the prevalence of tuberculosis in Western Europe peaked in the early 1800s and was the largest cause of death at the time. In the next 100 to 200 years tuberculosis spread to Eastern Europe, including Latvia and Poland, where Kernig and Brudzinski were conducting their research. ${ }^{23,24}$ In fact, Brudzinski noted 21 cases of tuberculous meningitis in his original description of 42 cases of meningitis. ${ }^{11}$

\section{Age Related Differences in Presentation}

It is important to note that Brudzinski, a pediatrician, and Kernig, a school physician, likely collected their anecdotal evidence through examination of children school-aged and younger. While the majority of the cases of meningitis occur in children under the age of two, with a peak incidence occurring at three to eight months of age, Kernig's sign, Brudzinski's sign, and nuchal rigidity are not accurate in diagnosing meningitis in infants younger than six months. $15,19,25$ In a study conducted by Guraraj et al, 18 Brudzinski's and Kernig's signs were found to be positive in only $18 \%$ and $19 \%$, respectively, of children with meningitis. Furthermore, the absence of the meningeal irritation in infants less than one month old resulted in incorrect diagnoses. 26,27 In a retrospective study conducted by Levy and Fried, ${ }^{15}$ as the age of patients with bacterial meningitis increased (from 2-24 months to 5-12 years), the sensitivity of Kernig's and Brudzinski's signs also increased. In another study conducted by Chotpitayasunondh, ${ }^{28}$ the sensitivity of Brudzinski's sign was again found to increase with age of patients with bacterial meningitis (11.5\% in neonates, $74.8 \%$ $>1$ month). As a result, Brudzinski's and Kernig's signs are not as frequently applied to young children as they are to adolescents and adults. ${ }^{29}$ Kernig's and Brudzinski's signs have also been proven ineffective in elderly populations. $15,21,26$ In a study conducted by Puxty et al, ${ }^{30}$ Kernig's sign was positive in $12 \%$ and Brudzinski's sign in $8 \%$ of geriatric patients without meningitis. Nuchal rigidity has been found to occur in up to $30 \%$ of the elderly population in the absence of meningitis. ${ }^{31}$ The presence of nuchal rigidity in the absence of meningitis, coupled with the increased prevalence of viral meningitis (less severe symptoms) and other underlying disease in geriatric patients, supports the general consensus that the diagnosis of meningitis in this population through the use of meningeal signs is inaccurate and ineffective. ${ }^{32}$

\section{Sensitivity and Specificity of Kernig's and Brudzinski's Signs}

Evaluation of the sensitivity and specificity of Kernig's sign does not adjust for the differences in current procedure of eliciting the sign from the original procedure as outlined by Kernig. ${ }^{10}$ In his original description he stated, "I am referring to the occurrence of flexion contractures in the legs or occasionally also in the arms which become evident only after the patient sits up," and "spasms in the extremities of recumbent patients are, as far as I have seen, present only intermittently." 23 While he performed the sign in patients sitting upright, textbooks of clinical medicine, pediatrics, and neurology routinely describe performing the test with the patient in the supine position. The advantage of evaluating neck stiffness in the sitting posture has been reproduced. ${ }^{33}$ In contrast, Brudzinski's sign is performed in the same fashion originally described. This equitable comparison may account for the reported discrepancy that Brudzinski's sign is often more sensitive than Kernig's sign. ${ }^{9,10,15}$

Surprisingly, there are few studies that explore the diagnostic efficacy of Kernig's and Brudzinski's signs. In 1999, a comprehensive review of all studies exploring the accuracy and precision of the clinical examination in the diagnosis of adult meningitis found only one study in which 34 cases of adult meningitis were analyzed and reported a sensitivity of $9 \%$ and specificity of $100 \%$ for Kernig's sign. ${ }^{14,16}$ It should be noted that this study excluded patients presenting with focal neurologic findings and mental status abnormalities, thus potentially excluding patients with a high likelihood of 
meningitis. Therefore, this study underestimated the diagnostic sensitivity of this sign. However, a more recent study, by Thomas et a ${ }^{17}$ analyzing 297 adults with suspected meningitis reported a sensitivity of $5 \%$ and specificity of $95 \%$ for both Kernig's and Brudzinski's signs.

These studies suggest that Kernig's and Brudzinski's signs are insensitive for detecting meningitis and therefore, when not present, should not be used to exclude the diagnosis of meningitis. The high specificity suggests that if Kernig's or Brudzinski's sign is present, there is a high likelihood for meningitis. In Kernig's original description of his sign in advanced cases of meningitis, pain may be elicited at angles of extension less than $90^{\circ}$, suggesting that the sensitivity of the sign may vary proportionately with severity of disease. However, Thomas et $\mathrm{al}^{17}$ showed that the sensitivities of Kernig's and Brudzinski's signs are not positively associated with the severity of the disease in subsets of patients with moderate meningeal inflammation or microbiological evidence of central nervous system infection. Additional studies evaluating the meningeal signs in certain subpopulations with meningitis are needed to determine their sensitivity and usefulness, as well as determine if there is a positive association between their sensitivity and severity of disease.

\section{Conclusion}

We may tend to overlook or underestimate the contributions of those astute clinicians of the past who, with minimal technology and no sophisticated laboratories at their disposal, built the foundation of clinical medicine through emphasis on the importance of the patient's history and physical examination. Although both Kernig's and Brudzinski's signs have low sensitivity but high specificity for diagnosis of bacterial meningitis, they have contributed to the construction of scoring algorithms incorporating meningeal signs and symptoms, working toward a standard of care to determine the need for lumbar puncture and empiric antibiotic therapy. Further prospective studies to evaluate the sensitivity and specificity of both Brudzinski's and Kernig's signs in various subpopulations (children, adults, geriatrics) need to be conducted. Positive elicitation of Brudzinski's and/or Kernig's signs in clinical evaluation of a patient suspected of meningitis can be confidently regarded as sufficient reason for proceeding with a lumbar puncture and treatment considerations; however, absence of these signs should not be used to rule out (exclude) the diagnosis of meningitis.

\section{References}

1. Swartz MN. Bacterial meningitis--a view of the past 90 years. N Engl J Med 2004;351:1826-1828.

2. Aronin SI, Peduzzi P, Quagliarello VJ. Community-acquired bacterial meningitis: risk stratification for adverse clinical outcome and effect of antibiotic timing. Ann Intern Med 1998;129:862-869.

3. Durand ML, Calderwood SB, Weber DJ, Miller SI, Southwick FS, Caviness VS Jr, Swartz MN. Acute bacterial meningitis in adults. A review of 493 episodes. N Engl J Med 1993;328:21-28.
4. Schuchat A, Robinson K, Wenger JD, Harrison LH, Farley M, Reingold AL, Lefkowitz L, Perkins BA. Bacterial meningitis in the United States in 1995. Active Surveillance Team. N Engl J Med 1997;337:970-976.

5. Arditi M, Mason EO Jr, Bradley JS, Tan TQ, Barson WJ, Schutze GE, Wald ER, Givner LB, Kim KS, Yogev R, Kaplan SL. Three-year multicenter surveillance of pneumococcal meningitis in children: clinical characteristics, and outcome related to penicillin susceptibility and dexamethasone use. Pediatrics 1998;102:1087-1097.

6. de Gans J, van de Beek D; European Dexamethasone in Adulthood Bacterial Meningitis Study Investigators. Dexamethasone in adults with bacterial meningitis. N Engl J Med 2002;347:1549-1556.

7. Proulx N, Frechette D, Toye B, Chan J, Kravcik S. Delays in the administration of antibiotics are associated with mortality from adult acute bacterial meningitis. QJM 2005;98:291-298.

8. Gopal AK, Whitehouse JD, Simel DL, Corey GR. Cranial computed tomography before lumbar puncture: a prospective clinical evaluation. Arch Intern Med 1999;159:2681-2685.

9. Saberi A, Syed SA. Meningeal Signs: Kernig's Sign and Brudzinski's Sign. Hospital Physician 1999;35:23-24.

10. Verghese A, Gallemore G. Kernig's and Brudzinski's signs revisited. Rev Infect Dis 1987;9:1187-1192.

11. Brody IA, Wilkins RH. The signs of Kernig and Brudzinski. Arch Neurol 1969;21:215-218.

12. Shulman ST, Friedmann HC, Sims RH. Theodor Escherich: the first pediatric infectious diseases physician? Clin Infect Dis 2007;45:1025-1029.

13. Kyle RA, Shampo MA. Jozef Brudzinski. JAMA 1979;241:1620.

14. Attia J, Hatala R, Cook DJ, Wong JG. The rational clinical examination: Does this adult patient have acute meningitis? JAMA 1999;282:175-181.

15. Levy M, Wong E, Fried D. Diseases that mimic meningitis. Analysis of 650 lumbar punctures. Clin Pediatr (Phila) 1990;29:254-5, 258-261.

16. Uchihara T, Tsukagoshi H. Jolt Accentuation of headache: the most sensitive sign of CSF pleocytosis. Headache 1991;31:167-171.

17. Thomas KE, Hasbun R, Jekel J, Quagliarello VJ. The diagnostic accuracy of Kernig's Sign, Brudzinski's Sign, and nuchal rigidity in adults with suspected meningitis. Clin Infect Dis 2002;35:46-52.

18. Gururaj VJ, Russo RM, Allen JE, Herszkowicz R. To tap or not to tap. What are the best indicators for performing a lumber puncture in an outpatient child? Clin Pediatr (Phila) 1973;12:488-493.

19. Pohl CA. Practical approach to bacterial meningitis in childhood. Am Fam Physician 1993;47:1595-1603.

20. Weisfelt M, de Gans J, van der Poll T, van de Beek D. Pneumococcal meningitis in adults: new approaches to management and prevention. Lancet Neurol 2006;5:332-342.

21. Weinstein L. Bacterial Meningitis: Specific etiologic diagnosis on the basis of distinctive epidemiologic, pathogenetic, and clinical features. Med Clin North Am 1985;69:219-229.

22. van Well GT, Paes BF, Terwee CB, Springer P, Roord JJ, Donald PR, van Furth AM, Schoeman JF. Twenty Years of pediatric tuberculous meningitis: a retrospective cohort study in the western cape of South Africa. Pediatrics 2009;123:e1-8.

23. Pearce JMS. The signs of Kernig and Brudzinski. J Neurol Neurosurg Psychiatry 1992;55:1141.

24. Daniel TM, Bates JH, Downes KA. History of Tuberculosis. In: Bloom B, ed. Tuberculosis. Washington, DC: ASM Press; 1994. 13-15.

25. Parkinson MS. Early recognition of symptoms in childhood meningitis. Practitioner 1972;209:191-195. 
26. Geiseler PJ, Nelson KE. Bacterial meningitis without clinical signs of meningeal irritation. South Med J 1982;75:448-450.

27. Romer FK. Difficulties in the diagnosis of bacterial meningitis: Evaluation of antibiotic pretreatment and causes of admission to hospital. Lancet 1977;2:345-347.

28. Chotpitayasunondh T. Bacterial meningitis in children: etiology and clinical features, an 11-year review of 618 cases. Southeast Asian J Trop Med Public Health 1994;25:107-115.

29. Oostenbrink R, Moons KG, Theunissen CC, Derksen-Lubsen G, Grobbee DE, Moll HA. Signs of meningeal irritation at the emergency department: how often bacterial meningitis? Pediatr Emerg Care 2001;17:161-164.

30. Puxty JA, Fox RA, Horan MA. The frequency of physical signs usually attributed to meningeal irritation in elderly patients. J Am Geriatr Soc 1983;31:590-592.

31. Mateen FJ, Mohr DN. 45-year-old woman with recurrent headache and photophobia. Mayo Clin Proc 2008; 83:951-955.

32. Choi C. Bacterial meningitis in aging adults. Clin Infect Dis 2001;33:1380-1385.

33. Vincent J, Thomas K, Mathew O. An improved clinical method for detecting meningeal irritation. Arch Dis Child 1993;68:215-218.

\section{Author Affiliations}

Michael A. Ward*; Tonia M. Greenwood*; David R. Kumar, BS ${ }^{\dagger}$; Joseph J. Mazza, $\mathrm{MD}^{\dagger}$; Steven H. Yale, $M D^{\dagger}$

*University of Wisconsin School of Medicine and Public Health, Madison, Wisconsin; tClinical Research Center, Marshfield Clinic Research Foundation, Marshfield Wisconsin 